\title{
A case study of using the hybrid model of scrum and six sigma in software development
}

\author{
Mona Najafi Sarpiri' ${ }^{1}$, Taghi Javdani Gandomani ${ }^{2}$ \\ ${ }^{1}$ Department of Computer Eng., Isfahan Branch, Islamic Azad University, Isfahan, Iran \\ ${ }^{2}$ Department of Computer Science, Shahrekord University, Shahrekord, Iran
}

\section{Article Info \\ Article history: \\ Received Oct 16, 2020 \\ Revised Apr 11, 2021 \\ Accepted Jun 12, 2021}

\section{Keywords:}

Agile methodologies

Agile software development

Hybrid methodologies

Scrum

Six sigma

\begin{abstract}
The world of software engineering is constantly discovering new ways that lead to an increase in team performance in the production of software products and, at the same time, brings the customer's further satisfaction. With the advent of agile methodologies in software development, these objectives have been considered more seriously by software teams and companies. Due to their very nature, agile methodologies have the potential to be integrated with other methodologies or specific managerial approaches defined in line with agility objectives. One of the cases is Six Sigma, which is used in organizations by focusing on organizational change and process improvement. In the present study, attempts were made to present the hybrid software development approach, including Scrum, as the most common agile and Six Sigma methodology. This approach was practically used in a case study, and the obtained results were analyzed. The results of this evaluation showed that this hybrid method could lead to the increased team performance and customer satisfaction. However, besides these two achievements, an increase in the number of re-works, number of defects discovered, and the duration of the project implementation were also observed. These cases are in line with the main objectives of Scrum and Six Sigma and are justifiable and acceptable due to achieving those objectives.
\end{abstract}

This is an open access article under the CC BY-SA license.

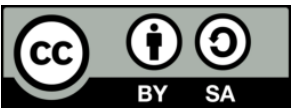

\section{Corresponding Author:}

Taghi Javdani Gandomani

Department of Computer Science

Shahrekord University

Rahbar Blvd., Shahrekord, Iran

Email: javdani@sku.ac.ir

\section{INTRODUCTION}

Software specialists have always sought solutions and methods to improve software development. In this path, the use of appropriate methodologies, new solutions, emerging technologies, and tools is considered [1]. Over the past years, the use of agile methodologies in software development has been the first option of the software companies and teams in the software project implementation. By focusing on the values such as paying attention to the customers and their changing needs, individuals and human interactions, avoiding development overheads, frequent and early delivery of the developed parts of the software, these methodologies seek to create higher performance in the software projects [2], [3].

Agile methodologies in software development include a set of methods, each of which considers a specific part of the product development process. Among the most important agile software development methodologies are Scrum, XP, Crystal, Kanban, feature-driven development (FDD), and test-driven development (TDD) [4]. Meanwhile, the use of Scrum combined with other methodologies, such as XP or Kanban, is the most popular and most common option considered by agile teams [3]. 
Literature review shows that the combination of software development methodologies has, in many cases, helped software teams achieve specific objectives. In fact, software teams combine software methodologies to use their strengths and enjoy their benefits together [5]-[7]. Meanwhile, sometimes software methodologies are combined with new standards and thoughts of productivity and management, which have resulted in increasing team productivity and customer satisfaction and improving the software development process [8]-[10].

Six Sigma is one of the successful strategies in the industry that pays special attention to achieving specific objectives, such as process performance, customer satisfaction, cost reduction, and quality increase [11]. Six Sigma is regarded as an organizational transformation strategy leading to the expansion and development of managerial methods in an organization. In this strategy, the measurement and evaluation of the improvement rate is a necessity to help managers make decisions about process improvement. Over recent years, this thinking has been used in software project implementation [12]-[14]. The objectives and values on which Six Sigma has been defined and developed seem to be aligned with the values and objectives pursued in agile software development processes. The combination of these two approaches can thus have positive effects. However, this may have overheads for agile development that partially take agile processes away from their ideals.

In the present case study, Scrum and Six Sigma frameworks were combined to investigate the effectiveness of using Six Sigma thinking and strategy in performing software projects. The rest of this article is organized as follows. In the second section, the agile approach and Scrum are introduced briefly. The third section is allocated to the brief introduction of Six Sigma. Section four shows how to use and integrate Scrum and Six Sigma. In Section five, the result of combining these two processes is evaluated in a case study. Finally, the last section concludes the paper.

\section{SCRUM AND AGILE SOFTWARE DEVELOPMENT}

The use of software development methodologies is regarded as an initial infrastructure for software project implementation. A software methodology shows the software development stages, how to develop a software product, and how to manage the development process. Over the last two decades, agile methodologies have taken the place of disciplined or plan-driven methodologies in the software world. In agile methodologies, the development method, values, and principles governing the development process and the project management method have undergone a serious change. That is why today, the past methodologies are known as traditional methodologies.

In software development, agile methodologies were formally introduced with the creation of the agile manifesto in 2001 [2]. However, in practice, it tooks the software industry some time to adapt to these new methodologies and use them in the software project implementation. What makes these methodologies popular is the values and principles on which these methods are defined. These values and principles are, in most cases, in contrast with the values and principles that have received attention in disciplined methodologies.

Though several agile methodologies have been proposed, all are a function of values and principles highlighted in the agile manifesto. The most common agile methodology is Scrum; whose special role is in managing software projects. This methodology emphasizes the iterative development of the product over short-term intervals called Sprints. In this methodology, the three key roles of master Scrum, product owner, and development team members are the only roles considered during the software product development [15]. The traditional responsibilities in a software development team are assigned to these roles [16]. Owing to the proper agility of this methodology and its main role in managing the project, many aspects of product development are not specified in this methodology, and software teams are free to consider them based on their needs and capabilities [17]. That is why this methodology has a high potential to be combined with other methodologies, standards, and management approaches. The existence of various hybrid solutions with regard to this methodology is rooted in this fact [5], [7], [18]-[20].

As shown in Figure 1, Scrum process is a three-step process. The team focus in the first step, called the pre-game phase, is on preparing the project implementation environment and defining the generalities and initial architecture of the product. The second phase, called game or development, is allocated to the iterative process of the product development. In each iteration, a part of the product is prepared and can be delivered. The third step, called the post-game phase, emphasizes the integration of the developed parts and the final product testing and delivery to the customer.

Over recent years, Scrum has been widely used in software companies such that it is known as the most popular agile methodology [3]. Of course, this may be caused by several problems that software teams and companies often experience in managing software projects. The problems that have made the use of Scrum a managerial requirement in these projects. 


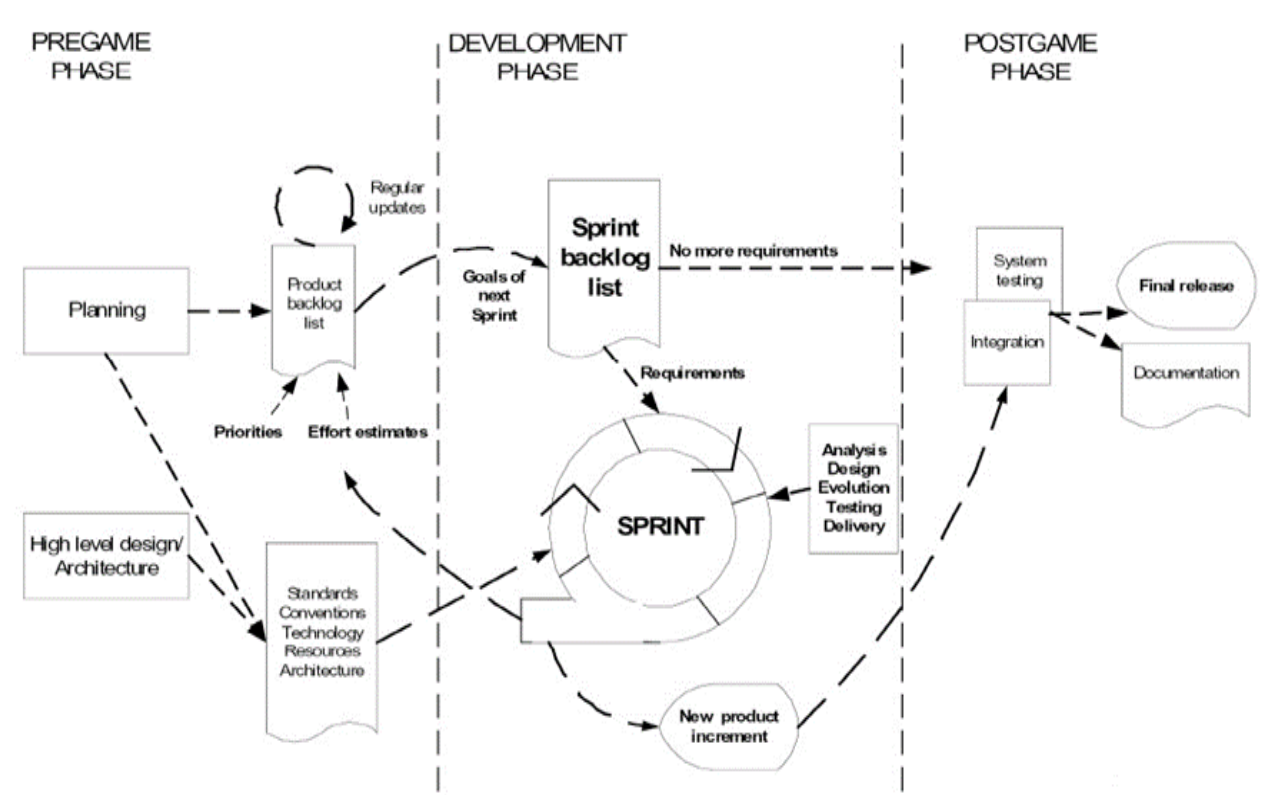

Figure 1. Scrum process in software development [4]

\section{SIX SIGMA}

In most companies and organizations, Six Sigma means a measure of quality that tends toward the ultimate quality. This concept is regarded as Six Sigma, or perfection, or complete satisfaction of the customer. But, in a sense, Six Sigma is a disciplined data-driven methodology in quality management used for defects elimination and reduction in executive processes. These processes can embrace all industrial, manufacturing, and service processes [18], [21].

The Six Sigma statistics-based approach quantitatively shows how a process is implemented. To achieve this objective, the maximum defect and failure in a process should not be more than 3.4 defects per million based on the Six Sigma approach [18]. Any defect in Six Sigma is anything that is not within the customer's needs and requirements. The final objective of Six Sigma is to implement a measurement-based strategy that focuses on process improvement and qualitative deviations reduction through the implementation of the Six Sigma recovery mechanisms. To this purpose, Six Sigma uses two sub-processes: DMAIC and DMADV [9], [18].

As shown in Figure 2, the Six Sigma DMAIC process is a system for improving the existing process [9]. This process includes define, measure, analyze, improve, and control stages. DMADV process is an improvement process that focuses on new processes and products based on the expected quality levels of Six Sigma [9]. As shown in Figure 3, this process includes define, measure, analyze, design, and verify stages. The reason why Six Sigma emphasizes on measurement is the fact that improvement is impossible without measuring and analyzing its results [19]. That is why these steps are seen in both sub-processes of Six Sigma.

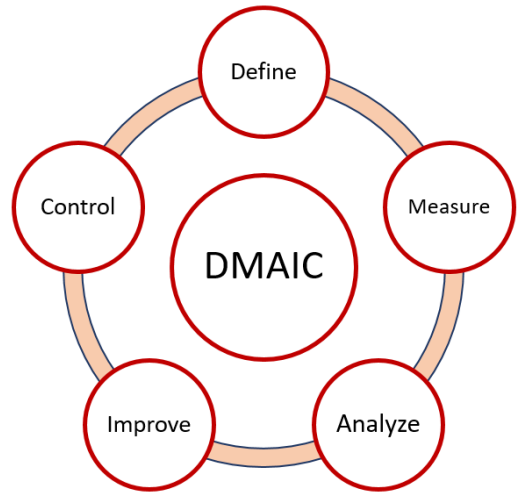

Figure 2. Six Sigma DMAIC process

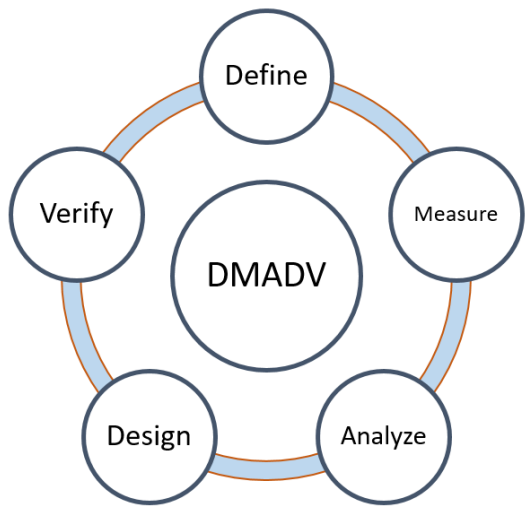

Figure 3. Six Sigma DMADV 


\section{COMBINATION OF SCRUM AND SIX SIGMA}

The simultaneous use of Scrum and Six Sigma seems to be a logical option for software companies to enjoy the benefits and values promised in both thoughts simultaneously. The important point is how one can use Six Sigma in a company or software team that uses Scrum [22], [23]. To this purpose, the requirements of Six Sigma somehow needed to be used in the Scrum framework.

As the basis of Six Sigma is measurement and measurement-based improvement, this requirement somehow should be seen in the scrum process steps. The first step of Six Sigma is defining phase, which can be used transparently in the contract and the initial requirements of the project implementation, project objectives, financial effects assessment, and the team members' performance. Additionally, the productivity index- related criteria and the analytical statistics required to determine the scope of the project should be defined simply and clearly [24]. The measure phase is the second phase in the Six Sigma. In this phase, the SIPOC diagram is used to determine the relevant elements of the project that needs improvement. This is done prior to the project onset [25]. Each of the executive elements in a Sprint should be documented and considered based on their inputs and outputs, tasks to be done in them, the persons in charge, and the time required for each activity [24]. In addition, the cause-effect diagram and analysis should be used for the problems occurring during Sprint, daily Scrum, review meeting, and retrospective meeting. The input and output of the development process should also be considered properly. In this section, the appropriate matrices are required to be used to analyze the profit and cost, and the priorities required by the customer. Finally, an appropriate measurement and inspection system is needed to be defined to ensure the accuracy of the data collection process.

The third step of Six Sigma is the analyze phase. The fault tree analysis diagram can be used in this step to find the root cause of a fault [24]. Moreover, regression analyses can be used to model the relation between and dependence of the process input and output variables. This can be used to analyze the positive or negative events that occurred in the development process and make it possible to discover defects and eliminate them. In the improve phase of Six Sigma, an executive plan is created in which the measures required to be taken during daily Scrum, review meeting, and retrospective meeting have been specified. Updating SIPOC and the initial process map by considering the executive plan implementation can be a great help in this section. In this section, the effectiveness of the taken improvement measures should be evaluated and analyzed.

In the control phase, a control plan is required to be created based on the critical inputs analyses, which properly show the result of the performance indices and can be used as a control tool to monitor the probable improvements occurred in processes and individuals. For Six Sigma to be deployed properly, the following can be used as executive principles during the scrum development process [13], [14], [24], [25]:

- Implementing DMAIC process in each Sprint

- Using process maps to create Sprint backlogs

- Determining the reason for defects or faults in the review and retrospective meetings

- Prioritizing the product backlog given the improvements expected by the customer

Overall, it seems that the use of Six Sigma in the scrum process, qualitative improvements, and scrum objectives can be properly considered, and the synergy of these two approaches leads to better achievement of these objectives. But there may be overheads to be considered in practical investigations.

\section{CASE STUDY}

One of the appropriate options to evaluate the combination of methodologies is to use case studies. In the present study, the hybrid Scrum with Six Sigma was used in a case study. In this case study, the hybrid method was used in a project in the health domain. The above-mentioned project was implemented in the form of three separate teams. Table 1 shows the teams' characteristics.

Table 1. Team's specifications

\begin{tabular}{cccc}
\hline Team & Size & Avg. work experience & Avg. cooperation in team \\
\hline Team1 & 6 & 4.5 & 3.1 \\
Team2 & 5 & 4.3 & 3.3 \\
Team3 & 6 & 4.7 & 3.4 \\
\hline
\end{tabular}

The composition of these teams was considered by the senior management of the company before the project onset. In this composition, attempts were made to keep teams at the same level of workability and engineering. To reduce the impact of selecting the volunteering team, a draw was made between the three teams for the hybrid method implementation, and Team1 was selected as the team to be studied. The other 
two teams were regarded as the control teams in this research. Team 1 received justification for using the hybrid methodology, and subjects were provided with the required training in this regard, and the required forms and procedures were prepared to implement and consider Six Sigma.

To evaluate the effectiveness of the hybrid methodology, the following variables were considered and gathered in all three teams during the Sprints implementation.

- Number of discovered defects in each Sprint

- Amount of re-works (the user stories transferred from the previous to the current Sprint)

- Team performance (resulting from the amount of the end-user stories selected in each Sprint)

- Amount of customer satisfaction (customer self-reporting in the Sprint review meeting)

Considering the contract negotiations with the customer, it should be noted that the length of the Sprints of this project was considered to be one week. The product backlog was the same in this project, and each team selected user stories from this backlog based on customer preferences. The nature of the project was thus the same for each of the three teams, and there was no damage to the research and its results. In the following, the results of data collection with regard to the variables of this research are addressed.

\subsection{Detected defects}

From one point of view, the defects discovered in each Sprint indicate the team's accuracy in performing its tasks. The more the team can obtain a degree of executive quality where fewer defects are observed, the higher the quality of the development process implementation. Table 2 shows the defects observed during the project in the project Sprints.

The statistics mentioned above show that the total of the defects observed in Team1 is in total less than that of the other two teams. Also, observing these defects in Team 1 has been a downward trend, indicating that this team has outperformed the other two ones. The point is that overall, Team 1 implemented one Sprint more than the other two teams. Figure 4 shows the statistics of the defects discovered in three teams.

Table 2. Defects observed during the project (in each Sprint)

\begin{tabular}{ccccccccccc}
\hline Team & SP1 & SP2 & SP3 & SP4 & SP5 & SP6 & SP7 & SP8 & SP9 & Sum \\
\hline Team1 & 5 & 5 & 4 & 3 & 4 & 3 & 3 & 2 & 2 & 31 \\
Team2 & 4 & 5 & 5 & 4 & 5 & 4 & 4 & 4 & - & 35 \\
Team3 & 5 & 6 & 5 & 3 & 4 & 5 & 6 & 5 & - & 39 \\
\hline
\end{tabular}

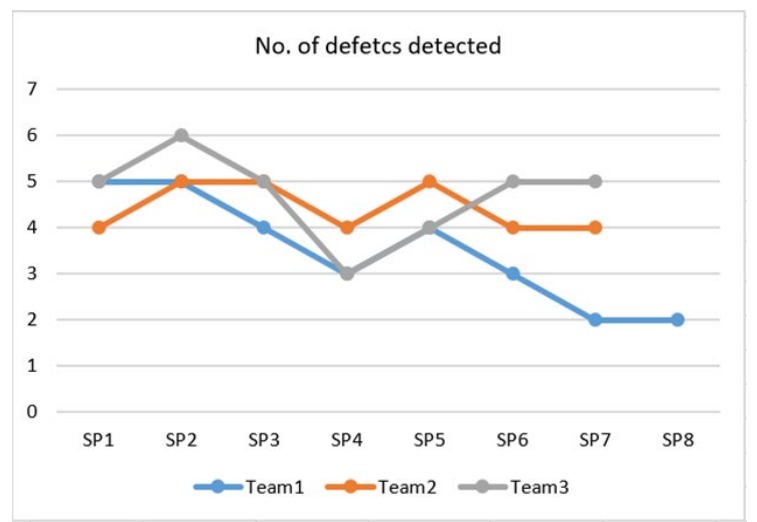

Figure 4. Number of defects detected in the teams

\subsection{Re-works}

This criterion shows the extent to which teams are required to perform things again. This requirement can be caused by performing inspections and considering the evaluation criteria. In calculating the re-works in this research, the amount of user stories that teams have to implement again in the next Sprint is considered. The lower the volume of the user stories, the higher the team accuracy in performing tasks. Table 3 shows the statistics related to this criterion.

As can be observed, the amount of re-works in Team 1 is greater than the other two teams. This is probably caused by the use of measurements and evaluations required by Six Sigma for the team understudy. In fact, to achieve the Six Sigma objectives, the team seems to be sometimes forced to do more things. This 
may be regarded as a negative point, but is justifiable with regard to achieving higher quality and customer satisfaction. Figure 5 shows the number of re-works in the case study teams.

Table 3. Number of User Stories transferred from the previous sprint (re-works)

\begin{tabular}{ccccccccccc}
\hline Team & SP1 & SP2 & SP3 & SP4 & SP5 & SP6 & SP7 & SP8 & SP9 & Sum \\
\hline Team1 & 0 & 18 & 25 & 20 & 17 & 25 & 30 & 22 & 0 & 175 \\
Team2 & 0 & 20 & 20 & 10 & 15 & 16 & 14 & 10 & 0 & 105 \\
Team3 & 0 & 15 & 17 & 15 & 10 & 20 & 15 & 14 & 0 & 106 \\
\hline
\end{tabular}

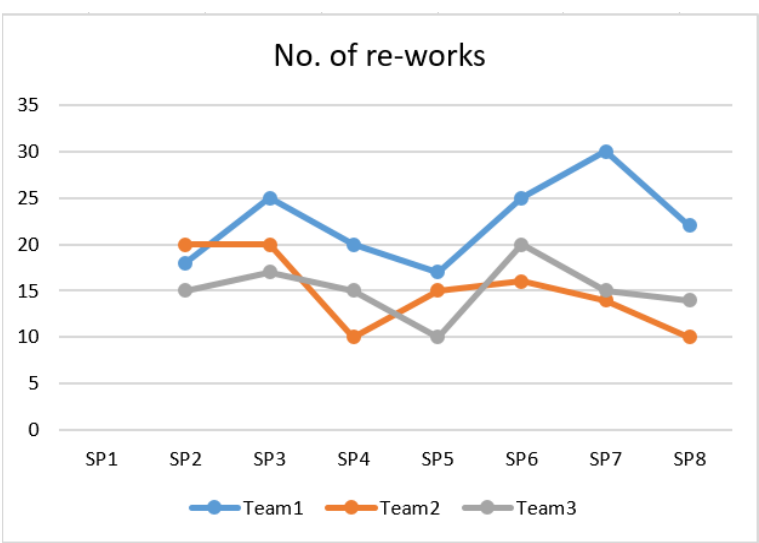

Figure 5. Number of re-works in the case study teams

\subsection{Team performance}

One of the other comparison criteria in this research is the team performance. In this research, the amount of the work done (end-user stories in each Sprint) to the committed work (selected user stories in each Sprint) ratio was used. The statistics are shown in Table 4.

As can be observed, the team performance in Team 1 is higher than the other two teams. This increase indicates that the effectiveness of Scrum and Six Sigma together has led to an increase in team performance. Also, the synergy of these approaches appears to be effective in line with their common objectives. Figure 6 demonstrates the above statistics.

Table 4. Team performance in teams' understudy (percentage)

\begin{tabular}{cccccccccc}
\hline Team & SP1 & SP2 & SP3 & SP4 & SP5 & SP6 & SP7 & SP8 & Average \\
\hline Team1 & 78 & 82 & 83 & 84 & 83 & 89 & 87 & 87 & 74.8 \\
Team2 & 80 & 76 & 76 & 80 & 78 & 85 & 85 & - & 70 \\
Team3 & 77 & 79 & 83 & 82 & 80 & 80 & 80 & - & 70.1 \\
\hline
\end{tabular}

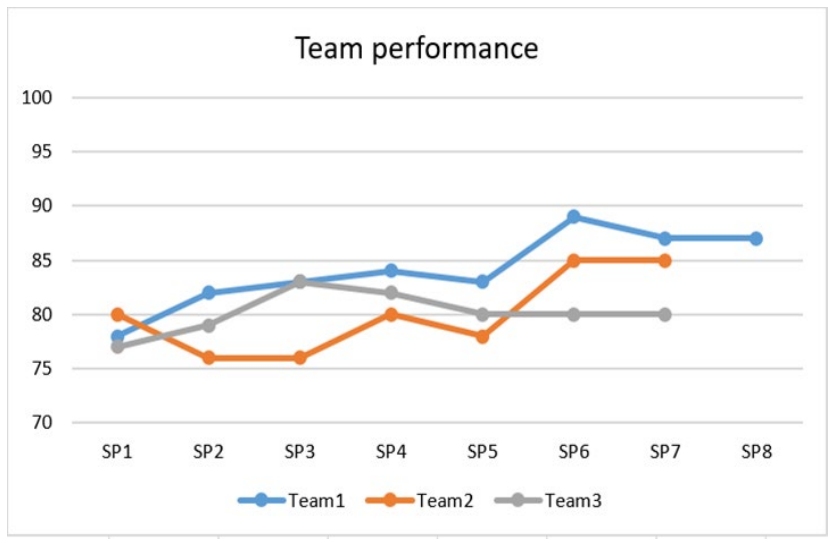

Figure 6. Team performance in the team's understudy 


\subsection{Customer satisfaction}

In this research, the customer was asked about customer satisfaction, which is one of the main objectives of Scrum and Six Sigma, by several questions via a self-reporting form. Finally, the customer was asked to express his absolute satisfaction in percentage. Table 5 shows these statistics.

Table 5. Customer satisfaction in the team's understudy (percentage)

\begin{tabular}{ccccccccccc}
\hline Team & SP1 & SP2 & SP3 & SP4 & SP5 & SP6 & SP7 & SP8 & SP9 & Average \\
\hline Team1 & 85 & 85 & 85 & 85 & 90 & 95 & 90 & 90 & 95 & 88.9 \\
Team2 & 85 & 80 & 80 & 85 & 80 & 85 & 85 & 85 & - & 83.1 \\
Team3 & 75 & 75 & 70 & 80 & 80 & 90 & 85 & 80 & - & 79.4 \\
\hline
\end{tabular}

As can be observed, approximately in all Sprints, the customer satisfaction reported by the customer on the performance of Team1 has been higher than the other two teams. This criterion indicates the success of the hybrid methodology in achieving the particular objective of increasing customer satisfaction. The customer satisfaction trend is shown in Figure 7.

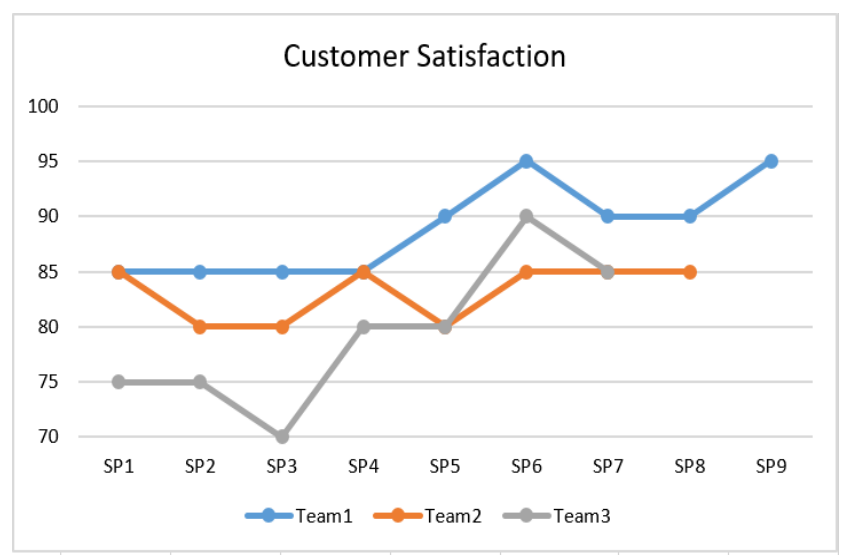

Figure 7. Customer satisfaction in the team's understudy

\section{CONCLUSION}

The use of hybrid methodologies in software development is one of the solutions used by software engineers to achieve greater competitiveness and higher quality of software products. This combination can include methodologies, approaches, and quality and managerial standards. Today, the use of Scrum has a particular place in most software teams. However, these teams also attempt to use the strengths of other standards and methodologies. The Six Sigma methodology is one of the managerial approaches that help companies achieve higher quality and greater customer satisfaction through the manufacturing and service processes improvement. In the present study, a combination of Scrum and Six Sigma was proposed and investigated. This hybrid method was used in a real-world case study and evaluated experimentally. The results obtained from this case study showed that the above hybrid method led to an increase in team performance and customer satisfaction. However, the amount of the discovered defects, re-works, and duration of the project implementation were higher in the team that used the hybrid method than the other teams that only used Scrum. Of course, the increased amount of the discovered defects and re-works seems to be caused by the higher accuracy and obsession in achieving quality criteria. This increase is justifiable from this perspective. But it seems that due to the overheads caused by doing more work and the team responsibilities resulting from the use of Six Sigma, the execution time of the work will increase. But due to the overheads caused by doing more work and the team responsibilities resulting from the use of Six Sigma, the duration of the project implementation seems to increase.

\section{ACKNOWLEDGEMENTS}

The authors would like to thank the teams that voluntarily participated in this study. Without their help and support, this study could not be completed. 


\section{REFERENCES}

[1] P. Tell et al., "What are hybrid development methods made of? an evidence-based characterization," in 2019 IEEE/ACM International Conference on Software and System Processes (ICSSP), 2019, pp. 105-114, doi: 10.1109/ICSSP.2019.00022.

[2] K. Beck et al., "Agile Manifesto," agilemanifesto.org. accessed June 2020. [Online]. Available: http://www.agilemanifesto.org

[3] Version One, "14 annual state of Agile report," digital.ai ${ }^{\mathrm{TM}}$. accessed June 2020. [Online]. Available: https://stateofagile.com/\#ufh-c-7027494-state-of-agile,

[4] P. Abrahamsson, O. Salo, J. Ronkainen, and J. Warsta, "Agile software development methods: Review and analysis," 2017, arXiv preprint arXiv:1709.08439.

[5] D. Castilla, "A Hybrid Approach Using RUP and Scrum as a Software Development Strategy," UNF Graduate Theses and Dissertations, Dept. Computing, University of North Florida. School of Computing, Florida, USA, 2014. [Online]. Available: https://digitalcommons.unf.edu/etd/514

[6] M. Kuhrmann et al., "Hybrid Software Development Approaches in Practice: A European Perspective," in IEEE Software, vol. 36, no. 4, pp. 20-31, Jul-Aug. 2019, doi: 10.1109/MS.2018.110161245.

[7] M. Kuhrmann et al., "Hybrid software and system development in practice: waterfall, scrum, and beyond," in Proceedings of the 2017 International Conference on Software and System Process, 2017, pp. 30-39, doi: $10.1145 / 3084100.3084104$.

[8] M. Esteki, T. J. Gandomani, and H. K. Farsani, "A risk management framework for distributed scrum using PRINCE2 methodology," Bulletin of Electrical Engineering and Informatics, vol. 9, no. 3, pp. 1299-1310, June 2020, doi: 10.11591/eei.v9i3.1905.

[9] M. Mousaei and T. J. Gandomani, "A new project risk management model based on scrum framework and Prince2 methodology," International Journal of Advanced Computer Science and Applications, vol. 9, no. 4, pp. 442-449, 2018, doi: 10.14569/IJACSA.2018.090461.

[10] M. Uddin, A. H. Jahin, and M. M. Hasan, "A Hybrid Framework for Interconnecting Various Software Engineering Process Models and Techniques," in ICCA 2020: Proceedings of the International Conference on Computing Advancements, 2020, pp. 1-4, doi: 10.1145/3377049.3377065.

[11] T. Pyzdek and P. Keller, "The six sigma," Estados Unidos: Mcgraw-hill, 2003.

[12] D. Grant and A. E. Mergen, "Towards the use of Six Sigma in software development," Total Quality Management, vol. 20, no. 7, pp. 705-712, Jul. 2009, doi: 10.1080/14783360903036962.

[13] A. M. E. Hamid, "Application of Six Sigma Methodology in Software Development," in 2018 International Conference on Computer, Control, Electrical, and Electronics Engineering (ICCCEEE), 2018, pp. 1-5, doi: 10.1109/ICCCEEE.2018.8515773.

[14] H. Pournaghshband, "Blending Six Sigma and Software Development," in Proceedings of the Future Technologies Conference (FTC) 2019, 2019, pp. 619-624, doi: 10.1007/978-3-030-32523-7_45.

[15] K. S. Rubin, "Essential Scrum: A Practical Guide to the Most Popular Agile Process," Michigan: Addison-Wesley Professional, USA, 2012.

[16] T. J. Gandomani, Z. Tavakoli, H. Zulzalil and H. K. Farsani, "The Role of Project Manager in Agile Software Teams: A Systematic Literature Review," in IEEE Access, vol. 8, pp. 117109-117121, 2020, doi: 10.1109/ACCESS.2020.3004450.

[17] M. Hron and N. Obwegeser, "Scrum in practice: an overview of Scrum adaptations," in Proceedings of the 51st Hawaii International Conference on System Sciences, 2018, doi: 10.24251/HICSS.2018.679.

[18] B. G. Tavares, C. E. S. da Silva, and A. D. de Souza, "Risk management analysis in scrum software projects," International Transactions in Operational Research, vol. 26, no. 5, pp. 1884-1905, 2019, doi: 10.1111/itor.12401.

[19] Z. Tavakoli, T. Gandomani, and M. Ghasemi, "Adaptation of scrum activities and artifacts to Milton's knowledge management model," Journal of Software Engineering \& Intelligent Systems, vol. 2, no. 3, pp. 226-230, 2017.

[20] A. Reddy, "The Scrumban [r] evolution: Getting the Most Out of Agile, Scrum, and Lean Kanban," AddisonWesley Professional, USA, 2015.

[21] V. Bubevski, "A Six Sigma Security Software Quality Management," Journal of Computer and Communications, vol. 4, no. 13, pp. 40-60, 2016, doi: 10.4236/jcc.2016.413004.

[22] G. Improta et al., "Agile Six Sigma in Healthcare: Case Study at Santobono Pediatric Hospital," International Journal of Environmental Research and Public Health, vol. 17, no. 3, 2020, Art. no. 1052, doi: 10.3390/ijerph17031052.

[23] A. Happy, "A systematic literature review of hybrid approaches of lean, agile and six sigma philosophies in supply chain management," Thesis, Western Sydney University, 2019.

[24] A. Correia, A. Gonçalves, and S. Misra, "Integrating the Scrum Framework and Lean Six Sigma," in International Conference on Computational Science and Its Applications, 2019, pp. 136-149, doi: 10.1007/978-3-030-24308$1 \_12$.

[25] K. Sanford, "The applications of scrum and six sigma to the software industry," Technical Report, 2017. Accessed: Sep. 2020. [Online]. Available: http://www.karisanford.com/ResearchPapers/SixSigmaSCRUMSoftwareInd.pdf 


\section{BIOGRAPHIES OF AUTHORS}

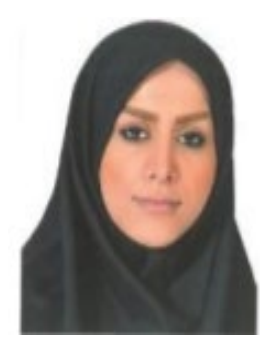

Mona Najafi Sarpiri is a Ph.D. student in software engineering at Isfahan Branch, Islamic Azad University, Isfahan Iran. She is currently pursuing her Ph.D. in Agile software development and hybrid methodologies.

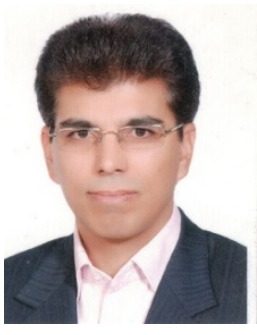

Taghi Javdani Gandomani, Senior Member, IEEE, received the Ph.D. degree from Universiti Putra Malaysia (UPM), Malaysia in 2014. He is currently an Assistant Professor of Software Engineering at Shahrekord University, Iran. His research interests include Agile software development, software process improvement, software project management, and empirical software engineering. He is also leader of data science Lab in Shahrekord University, Iran. 